\title{
Surgical Oncology: Clinical Importance
}

Federico Coccolini' ${ }^{1}$, Fausto Catena ${ }^{4}$, Michela Giulii Capponi' ${ }^{1}$, Elia Poiasina ${ }^{1}$, Elena Rota Caremoli ${ }^{3}$, Paolo Bertoli' ${ }^{1}$, Michele Masetti ${ }^{2}$, Elio Jovine ${ }^{2}$, Luca Ansaloni ${ }^{1}$ and Salomone di Saverio ${ }^{2 *}$

${ }^{1}$ General and Emergency Surgery Department, Ospedali Riuniti, Bergamo, Italy

${ }^{2}$ General Surgery Department, Ospedale Maggiore, Bologna, Italy

${ }^{3}$ Oncology Department, Ospedali Riuniti, Bergamo, Italy

${ }^{4}$ General and Emergency Surgery Department, Ospedale Maggiore, Parma, Italy

In the last 20 years the surgical panorama has deeply changed, especially in the oncologic field. In the past the oncologic surgeon had at his disposal few weapons in addition to his surgical capability. Yearby-year the scientific progress has registered remarkable improvements in all the disciplines and the cancer treatment potential has been increased.

Moreover adjuvant and neo-adjuvant chemotherapy has been implemented up to be less harmful but more effective in fighting cancer. Different ways of its administration have been applied to different primary neoplasm; from the nebulized chemotherapies for lung cancer to the hyperthermic intra-peritoneal chemotherapy (HIPEC), which has demonstrated very good results not only in uncommon tumors like pseudomixoma peritonei, but also in gynecologic, colon and gastric cancer. Actually HIPEC allows reaching good survival results with acceptable morbidity rate; at the same time it reduces the systemic toxicity due to chemo-therapics [1]. The employment of neo-adjuvant chemotherapy regimens has demonstrated to reduce the surgical effort and the morbidity rate $[2,3]$.

The introduction of radiotherapy has radically changed prostate and rectal cancer prognosis. Neo-adjuvant chemo-radio therapy combined regimens reduce the recurrence rate and the complications due to extended surgery $[4,5,6,7]$. In prostate cancer, as in breast, rectal and anal verge cancer brachytherapy has demonstrated its usefulness also in the management of advanced disease [8,9]. Moreover in breast cancer the intraoperative radiotherapy [IORT] and the electron intraoperative radiotherapy (ELIOT) allow the treatment of locally advanced stages with tissue sparing techniques and immediate reconstructive plastic surgery $[10,11]$.

New prospects have been also opened with the discovery of immunotherapy. Now monoclonal antibodies are commonly used, besides palliative chemotherapy, to treat advanced tumors.

Lastly new interest has been concentrated on rare tumors, such as some forms of sarcomas or gastrointestinal stromal tumors (GISTs). For these uncommon neoplasms the role and the time of surgery are complex and not always well established. Surgery can be used more than once during the course of cancer management: for diagnosis, for treatment and also for palliation. In the meantime the target therapy has become the cornerstone of treatment for such unusual diseases and debulking procedures can support its action in advanced staged cancer $[12,13]$.

For all the above-mentioned reasons cancer represents an area of multidisciplinary expertise. On one hand it is expected that modern surgical oncologists possess an understanding of the biology of cancer, methods of diagnosis and staging and the variety of treatment options available beyond surgical approaches. On the other hand decision making should be shared by a dedicated team of specialists. Multidisciplinary and/or interdisciplinary work has proven to be most effective when team members have professional and personal commitment to care and common goals for healthcare outcomes.
The conditions necessary to achieve a profitable activity are the clarification of the rule of the team, the support and respect of other team members for their contribution, good communication among the team members and the right environment that promotes these factors [14]. Unfortunately multidisciplinary team could be very expensive if each member brings only his own perspective by suggesting tests, consultations and treatments that are not evidence-based and are of little benefit to patient's condition. The resultant quality and cost benefit to the patient and the system depend on the way in which the team is managed and led [15].

The widespread of the concept of multidisciplinary teams has strongly reduced the invasiveness of oncologic surgery, resulting also in lowered morbidity rate. In the meantime all the complementary tools have refined their impact and chemotherapy has reduced its collateral effects. The final effect of this process has led to better clinical outcomes, in terms of quality of life, oncological results and patient satisfaction. Furthermore an increasing number of older and complicated patients can be recruited with therapeutic intent.

However it should be kept in mind as quality and safety in medical care has historically suffered from having poor quality science. Lamb et al. reported that the scientific quality of studies on multidisciplinary teams is "low to medium". Better methods are needed to establish the benefit and the rules of such a common-sense team approach [16].

\section{References}

1. Ansaloni L, Agnoletti V, Amadori A, Catena F, Cavaliere D, et al. (2012) Evaluation of extensive cytoreductive surgery and hyperthermic intraperitoeal chemotherapy (HIPEC) in patients with advanced ovarian cancer. Int J Gynecol Cancer.

2. Vergote I, Tropé CG, Amant F, Kristensen GB, Ehlen T, et al. (2010) Neoadjuvant chemotherapy or primary surgery in stage IIIC or IV ovarian cancer. N Engl J Med 363: 943-953.

3. Ansaloni L, De laco P, Frigerio L. (2012) Re: "cytoreductive surgery and hyperthermic intraperitoneal chemotherapy as upfront therapy for advanced epithelial ovarian cancer: multi-institutional phase II trial." - Proposal of a clinical trial of cytoreductive surgery and hyperthermic intraperitoneal chemotherapy in advanced ovarian cancer, the CHORINE study. Gynecol Oncol 125: 279-281.

4. Zaorsky NG, Li T, Devarajan K, Horwitz EM, Buyyounouski MK (2012) Assessment of the American Joint Committee on Cancer staging (sixth and

${ }^{*}$ Corresponding author: Salomone di Saverio, General Surgery department, Ospedale Maggiore, Bologna, Italy, E-mail: salo75@inwind.it

Received May 13, 2012; Accepted May 14, 2012; Published May 16, 2012

Citation: Coccolini F, Catena F, Capponi MG, Poiasina E, Caremoli ER, et al (2012) Surgical Oncology: Clinical Importance. J Nucl Med Radiat Ther S2:e001. doi:10.4172/2155-9619.S2-e001

Copyright: (c) 2012 Coccolini F, et al. This is an open-access article distributed under the terms of the Creative Commons Attribution License, which permits unrestricted use, distribution, and reproduction in any medium, provided the original author and source are credited. 
seventh editions) for clinically localized prostate cancer treated with external beam radiotherapy and comparison with the National Comprehensive Cancer Network risk-stratification method. Cancer.

5. Ghadjar P, Zwahlen D, Aebersold DM, Zimmermann F (2012) Postoperative radiotherapy after radical prostatectomy: indications and open questions. Prostate Cancer.

6. Benson AB 3rd, Guillem JG, Minsky BD (2011) Have the changes in treatment of rectal cancer made a significant difference to our patients? Oncology (Williston Park) 25: 1323-1329.

7. Rödel C, Hofheinz R, Liersch T (2012) Rectal cancer: state of the art in 2012. Curr Opin Oncol.

8. Langley S, Ahmed HU, Al-Qaisieh B, Bostwick D, Dickinson L, et al. (2012) Report of a consensus meeting on focal low dose rate brachytherapy for prostate cancer. BJU Int 1: 7-16.

9. Budäus L, Bolla M, Bossi A, Cozzarini C, Crook J, et al. (2012) Functional outcomes and complications following radiation therapy for prostate cancer: a critical analysis of the literature. Eur Urol 61: 112-127.
10. De Lorenzi F, Lohsiriwat V, Barbieri B, Rodriguez Perez S, Garusi C, et al. (2012) Immediate breast reconstruction with prostheses after conservative treatment plus intraoperative radiotherapy. Long term esthetic and oncological outcomes. Breast.

11. Orecchia R, Leonardo MC (2011) Intraoperative radiation therapy: is it a standard now? Breast 3: S111-115.

12. Coccolini F, Catena F, Ansaloni L, Pinna AD (2012) Gastrointestinal stromal tumor and mitosis, pay attention. World J Gastroenterol 18: 587-588.

13. Coccolini F, Catena F, Ansaloni L, Lazzareschi D, Pinna AD (2010) Esophagogastric junction gastrointestinal stromal tumor: resection vs enucleation. World J Gastroenterol 16: 4374-4376.

14. Lewallen JP, Tuturro CR, Tuturro A (2010) Preventive Dermatology RO Norman ed. Springer Verlag, London 47-55.

15. Makary MA (2011) Multidisciplinary teams and clinics: better care or just more care. Ann Surg Oncol 18: 2105-2106.

16. Lamb BW, Brown KF, Nagpal K, Vincent C, Green JS, et al. (2011) Quality of care management decisions by multidisciplinary cancer teams: a systematic review. Ann Surg Oncol 18: 2116-2125.
This article was originally published in a special issue, Surgical oncology: Clinical Importance handled by Editor(s). Dr. Liqiang Zhang, Arizona State University, USA; Dr. Salomone Di Saverio, Surgery and Trauma Surgery Unit, Italy 